\title{
Фотолюминесценция ZnS : Cu в матрице полиметилметакрилата
}

\author{
(C) В.П. Смагин ${ }^{1}$, Н.С. Еремина ${ }^{2}$, М.С. Леонов ${ }^{1}$ \\ ${ }^{1}$ Алтайский государственный университет, \\ 656049 Барнаул, Россия \\ 2 Томский государственный университет, \\ 634050 Томск, Россия \\ E-mail: smaginV@yandex.ru
}

(Получена 13 ноября 2017 г. Принята к печати 22 ноября 2017 г.)

Методом возникающих реагентов непосредственно в среде (поли)метилметакрилата (ПММА) синтезированы квантовые точки $\mathrm{ZnS}: \mathrm{Cu}$, закрепленные в оптически прозрачной полимерной матрице. Светопропускание полимерных композиций в видимой области спектра достигает 92\% (при толщине 5 мм). Фотолюминесценция ПМMA/ZnS:Cu связана с дефектами кристаллической структуры $\mathrm{ZnS}$ и системой энергетических уровней, расположенных в запрещенной зоне сульфида цинка. Она зависит от концентрации ионов меди, перепоглощения излучения $\mathrm{ZnS}$ и ПММА, а также от других факторов.

DOI: $10.21883 /$ FTP.2018.08.46214.8729

\section{1. Введение}

Сульфид цинка является одним из наиболее широко применяемых люминофоров. В свете современных тенденций развития техники его исследования остаются актуальными и в настоящее время [1-7]. Наноразмерные кристаллы ZnS, пленки находят применение в оптике, электронике, биомедицине. Для их синтеза широкое распространение получили химические методы, в частности коллоидной синтез [8-11]. Внедрение квантовых точек (KT) $\mathrm{ZnS}$ в полимерную матрицу позволяет зафиксировать их пространственное положение, формируя морфологию образца. Применение метилметакрилата (MМА) в качестве реакционной среды позволяет синтезировать КТ сульфидов металлов непосредственно в полимеризуемой оптически прозрачной среде [10,11]. После радикальной полимеризации ММА образуются высокопрозрачные в видимой части спектра люминесцирующие полимерные „стекла“ $[12,13]$. Однако из-за перекрывания спектральных полос $\mathrm{ZnS}$ и полиметилметакрилата (ПММА) вероятны процессы перепоглощения излучения с участием макромолекул и $\mathrm{ZnS}$. Одним из способов влияния на спектральные характеристики полупроводников является их легирование ионами металлов [14-21]. Применение этого способа может оказаться эффективным для синтеза люминесцирующих оптически прозрачных полимерных композиций с заданными спектральными характеристиками.

Цель работы заключалась в изучении влияния ионов меди на фотолюминесценцию квантовых точек $\mathrm{ZnS}: \mathrm{Cu}$ в среде (поли)метилметакрилата, а также в установлении влияния ПММА на люминесценцию в композициях ПMMA/ZnS : $\mathrm{Cu}$.

\section{2. Характеристика объектов исследования и методики эксперимента}

Квантовые точки $\mathrm{ZnS}$ и $\mathrm{ZnS}: \mathrm{Cu}$ синтезированы в среде метилметакрилата (Merck) с использованием вза- имодействия трифторацетатов цинка и меди с тиоацетамидом (ТАА) при нагревании [12]. В свою очередь трифторацетаты меди и цинка были синтезированы через взаимодействие оксидов цинка и меди с трифторуксусной кислотой в водной среде. Соли выделены в кристаллическом состоянии и идентифицированы методом инфракрасной спектроскопии. ТАА был очищен перекристаллизацией. Концентрация трифторацетата цинка и ТАА во всех растворах была равна 0.010 моль/л каждого. Концентрацию трифторацетата меди увеличивали до 0.010 моль/л, что соответствует увеличению мольных соотношений $\mathrm{Zn}: \mathrm{Cu}$ от 1:0 до 1:1. Об образовании КТ $\mathrm{ZnS}$ и $\mathrm{ZnS}: \mathrm{Cu}$ судили по опалесценции растворов.

В стеклообразное состояние коллоидные растворы КТ переведены радикальной полимеризацией ММА в блоке. Для этого в растворы вводили перекись бензоила в количестве $0.10 \%$ от массы ММА и нагревали при температуре $60-70^{\circ} \mathrm{C}$ до вязкого состояния. Вязкими растворами заполняли разборные стеклянные кюветы и продолжали нагревать до перехода композиций в стеклообразное состояние. Полимеризация продолжалась в течение 24 ч. По виду полимерные „стекла“ изменялись от бесцветных до имеющих слегка голубую окраску при увеличении концентрации меди.

Спектры поглощения в области 250-800 нм, возбуждения люминесценции и спектры люминесценции зарегистрированы на спектрофлуориметре СM 2203 („Solar“, Республика Беларусь). Спектры поглощения ПММА записаны относительно воздуха, спектры поглощения композиций ПММА/ZnS и ПММА/ZnS: $\mathrm{Cu}$ - относительно пластин ПММА сопоставимой толщины. При регистрации спектров люминесценции возбуждающий свет источника излучения (ксеноновая дуговая лампа высокого давления ДКсШ 150-1М) падал на образец перпендикулярно его поверхности. Стационарную фотолюминесценцию регистрировали под углом $45^{\circ}$. Спектры возбуждения регистрировали в максимумах полос люминесценции. Для исследования спектральных свойств вырезали пластины размером $2 \times 2$ см одинаковой толщины. 


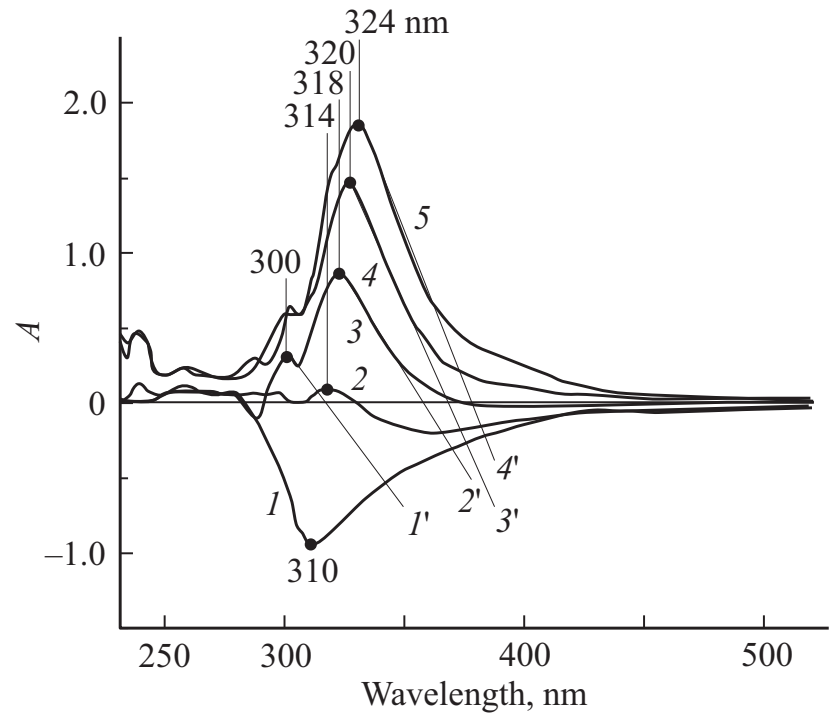

Рис. 1. Спектры поглощения композиции ПММА/ZnS: $\mathrm{Cu}$. Содержание ионов меди $C_{\mathrm{Cu}}$, моль/ $\langle 1$ л полимеризуемой смеси $\rangle$ (мольное соотношение $\mathrm{Zn}: \mathrm{Cu}): 1-0.00010$ (100:1), $2-0.0010(10: 1), 3-0.0050(2: 1), 4,5-0.010(1: 1)$. $4-\mathrm{Zn}: \mathrm{TAA}=1: 1,5-\mathrm{Zn}: \mathrm{TAA}=1: 2$, содержание ТАА $C_{\mathrm{TAA}}=0.010$ моль $/\langle 1$ л полимеризуемой смеси $\rangle$, содержание $\mathrm{Zn} C_{\mathrm{Zn}}=0.010$ моль $/\langle 1$ л полимеризуемой смеси $\rangle$.

\section{3. Результаты эксперимента и их обсуждение}

ПММА поглощает излучение с длиной волны $\lambda<300$ нм. В видимой области спектра пропускание пленок ПММА сопоставимо с пропусканием неорганических стекол, при толщине образцов 5 мм оно не превышает 92-93\%. В спектрах ПММА/ZnS наблюдается широкая полоса с максимумом в области $300 \mathrm{Hм.}$ Она отнесена к поглощению наночастиц $\mathrm{ZnS}$ [22]. После введения в состав композиций ионов меди в спектрах зарегистрирована сложная полоса в области длин волн $\lambda=280-(>400)$ нм (см. рис. 1 , на котором $A-$ оптическая плотность). Структура полосы связана с образованием нескольких видов поглощающих центров, в том числе с ионными парами $\mathrm{Cu}_{I}^{2+}-\mathrm{Cu}_{V}^{2+}$, образованными ионами меди, занимающими позиции в междоузлиях и вакансии в узлах кристаллической решетки $\mathrm{ZnS}$, и более сложными агрегатами [18]. При увеличении концентрации ионов меди интенсивность полосы увеличивалась. Максимум смещался в область длинных волн от 310 до 324 нм. Интенсивность полосы также возрастала при увеличении концентрации ТАА (рис. 1, спектры 4 и 5). Это связано с увеличением выхода сульфидов в процессе синтеза композиций. На восходящей ветви полосы в области 300 нм наблюдается максимум поглощения наночастиц $\mathrm{ZnS}$. Иной ход спектральной кривой 1 (рис. 1) связан с компенсацией энергии, поглощенной частицами $\mathrm{ZnS}: \mathrm{Cu}$, люминесцентным излучением $\mathrm{ZnS}$ при перекрывании полос поглощения и люминесценции.
Средний размер частиц $\mathrm{ZnS}$, рассчитанный с использованием спектральных данных по методике [23], составляет 5-6 нм (касательная $1^{\prime}$ проведена к ниспадающей ветви коротковолновой компоненты полосы поглощения в спектре 3 , связанной с $\mathrm{ZnS}$; точка пересечения касательной с осью длин волн соответствует 330 нм). Результат расчета совпадает с данными $[10,11,24,25]$. Легирование сульфида цинка ионами меди приводит к увеличению размера частиц. На это указывает длинноволновое смещение точки пересечения с осью абсцисс касательных $2^{\prime}-4^{\prime}$, проведенных соответственно к ниспадающим ветвям длинноволновых компонент полос поглощения в спектрах 3-5, связанных с легированием сульфида цинка. Увеличение размера легированных частиц объясняется искажением элементарной ячейки при внедрении ионов меди в пустоты кристаллической решетки $\mathrm{ZnS}$ и замещении ионов цинка в ее узлах [1]. К увеличению размера частиц также приводит образование комплексов на их поверхности, которое для аналогичных систем подтверждено результатами просвечивающей электронной микроскопии [11,24].

Полоса люминесценции ПММА расположена в области 400-480 нм. Соответствующая ей полоса в спектре возбуждения люминесценции находится в интервале длин волн 300-380нм (регистрация при 440нм). Интенсивность полос невысока. Их появление связано с продуктами разложения перекиси бензоила, которую использовали для инициирования полимеризации ММА при отверждении композиций.

Композиции ПММA/ZnS люминесцируют в области длин волн 300-600 нм (рис. 2). Структура и неоднородное уширение полосы объясняются полиморфизмом кристаллической структуры $\mathrm{ZnS}$ [26], незавершенностью ее формирования в ядрах коллоидных частиц, дисперсностью частиц $\mathrm{ZnS}$ и аморфностью полимерной матрицы. Кроме того, сказывается комплексообразование на поверхности частиц и наложение люминесценции ПММА. При возбуждении люминесценции излучением с длинами волн 230, 250, 270, 290, 310, 330 и 370 нм выделены отдельные компоненты полосы (рис. 2). Они также являются составными, неоднородно уширенными. По данным $[8,17]$, в этой области спектра наблюдается „самоактивированная“ люминесценция $\mathrm{ZnS}$. Ее „голубую“ составляющую связывают с вакансиями в подрешетке цинка $\left(V_{\mathrm{Zn}}\right)$ [8]. В экспериментальном спектре ей соответствует сложная полоса с максимумом в интервале длин волн 400-450 нм (рис. 2, спектры 6 и 7). По данным [8,27], она может иметь до четырех компонент. Максимумы отдельных компонент данной полосы располагаются при длинах волн 418, 425 и 450 нм. Полоса „зеленой“ люминесценции с максимумом в области 550 нм может быть связана с вакансиями в подрешетке серы $\left(V_{\mathrm{S}}\right)[14]$. Она возникает при рекомбинации свободного электрона с локализованной в центре свечения „дыркой“ (механизм Шёна-Клазенса) [1]. Кроме того, на спектр может оказывать влияние кислород, 
который относительно легко замещает атомы серы в узлах кристаллической решетки, создавая дополнительные дефекты в структуре $\mathrm{ZnS}$ [28]. Это влияние может рассматриваться как еще один из факторов неоднородного уширения спектральных полос.

На рис. 3 приведены нормированные спектры возбуждения люминесценции и люминесценции одного из образцов композиции ПММA/ZnS: Cu. Полоса в спектре возбуждения люминесценции $\mathrm{ZnS}: \mathrm{Cu}$ перекрывается с одной из полос люминесценции $\mathrm{ZnS}$ (рис. 2 и 3). Это подтверждает предположение относительно хода спектральных кривых на рис. 1. С увеличением концентрации ионов меди максимум полосы люминесценции $\mathrm{ZnS}: \mathrm{Cu}$ претерпевает батохромное смещение с 434 до $448 \mathrm{Hм}$ (рис. 4). Зависимость интенсивности люминесценции от концентрации меди нелинейная. Прирост пиковой интенсивности полос относительно интенсивности люминесценции полосы в спектре об-

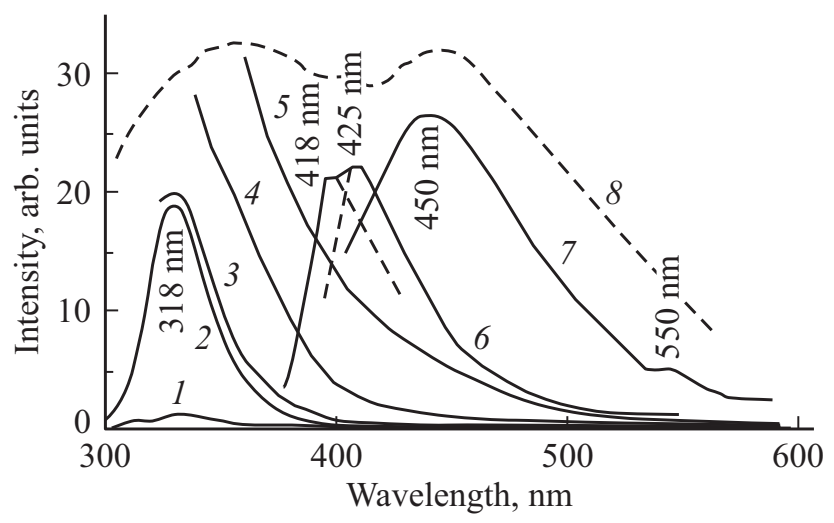

Рис. 2. Спектры люминесценции композиции ПММA/ZnS при возбуждении излучением с длиной волны, нм: $1-230$, $2-250,3-270,4-290,5-310,6-330,7-370$. 8 - контур сложной полосы.

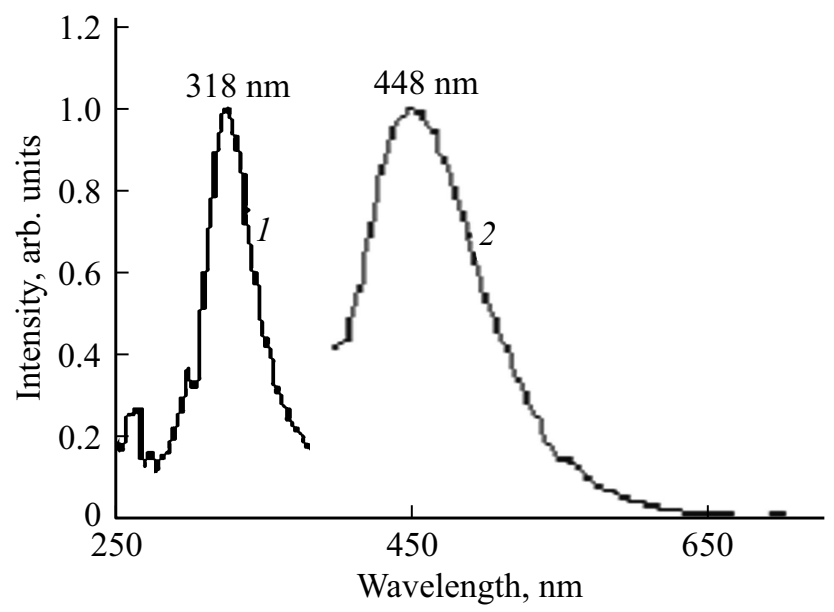

Рис. 3. Спектр возбуждения люминесценции (1, длина волны люминесценции 448 нм) и спектр фотолюминесценции (2, длина волны возбуждения $318 \mathrm{нм})$ композиции ПММА/ZnS: $\mathrm{Cu}$, $C_{\mathrm{Zn}}=C_{\mathrm{Cu}}=0.010$ моль $/\langle 1$ л полимеризуемой смеси $\rangle$.

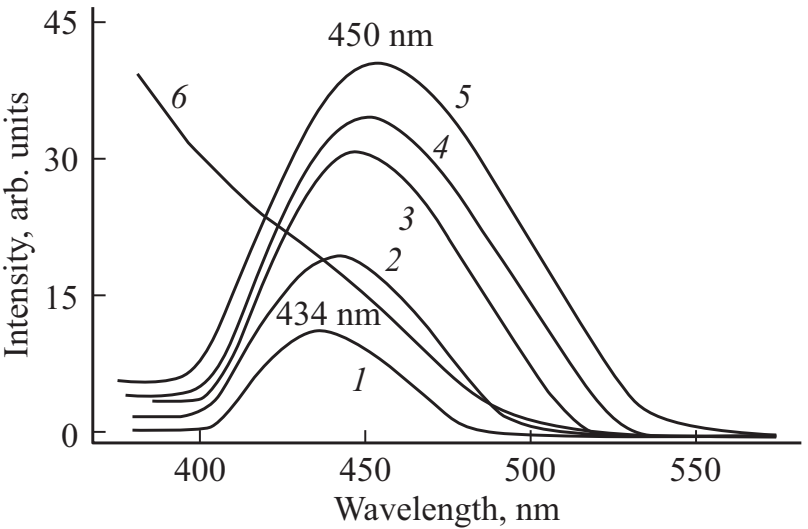

Рис. 4. Спектры люминесценции композиций ПММA/ZnS: $\mathrm{Cu}$ $(1-5$, длина волны возбуждения 318 нм). Содержание ионов меди, моль/ $\langle 1$ л полимеризуемой смеси $\rangle$ (длина волны максимума излучения, $\left.C_{\mathrm{Zn}}: C_{\mathrm{TAA}}\right): 1-0.00010(434 \mathrm{HM}, 1: 1)$, $2-0.0010$ (436 нм, $1: 1), 3-0.0050$ (444 нм, $1: 1), 4-0.010$ $(448$ нм, $1: 1), 5-0.010(450$ нм, $1: 2) .6-$ спектр люминесценции композиции ПММA/ZnS (длина волны возбуждения $310 \mathrm{HM} ; C_{\mathrm{Zn}}: C_{\mathrm{TAA}}=1: 1, C_{\mathrm{Zn}}=0.010$ моль $/\langle 1$ л полимеризуемой смеси $\rangle$.

разца с $C_{\mathrm{Cu}}=1.0 \cdot 10^{-4}$ моль/л составляет $1.6,2.3,2.6$. Причиной насыщения может быть образование ионных пар $\mathrm{Cu}_{I}^{2+}-\mathrm{Cu}_{V}^{2+}[18]$ или более сложных агрегатов меди с увеличением ее концентрации. Также сказывается перепоглощение излучения при перекрывании полос поглощения, включая полосы поглощения матрицы, и полос люминесценции. Исходя из этого, оптимальной, на наш взгляд, является концентрация меди не более $5.0 \cdot 10^{-3}$ моль/л. Кроме того, показана связь интенсивности люминесценции с концентрацией ТАА, взятого для проведения синтеза $\mathrm{ZnS}: \mathrm{Cu}$ (рис. 4, спектры 4 и 5). Рост интенсивности люминесценции объясняется увеличением выхода сульфида цинка в процессе синтеза, а также увеличением концентрации сульфидионов, которые создают в $\mathrm{ZnS}$ дополнительные дефекты, ответственные за возникновение люминесценции.

\section{4. Заключение}

Исходя из полученных результатов энергетические переходы в $\mathrm{ZnS}$ и $\mathrm{ZnS}: \mathrm{Cu}$ без учета состояний матрицы в наиболее общем виде можно представить схемой, приведенной на рис. 5. При ее составлении мы опирались на данные $[8,28,29]$. На схеме $E_{C}$ и $E_{C}^{\prime}-$ положение дна зоны проводимости в монокристалле $\mathrm{ZnS}$ и в наночастицах в матрице ПММА. На вставке к рисунку 5 (рис. 5 , справа выше) приведены излучательные переходы в ZnS. Штриховая стрелка показывает положение вставки на общей диаграмме (рис. 5). Переходы 1 и 2 соответствуют поглощению энергии $\mathrm{ZnS}$. Диапазону энергий от 5 до 4 эВ в спектре поглощения соответствует набор сложных полос (интервал длин 


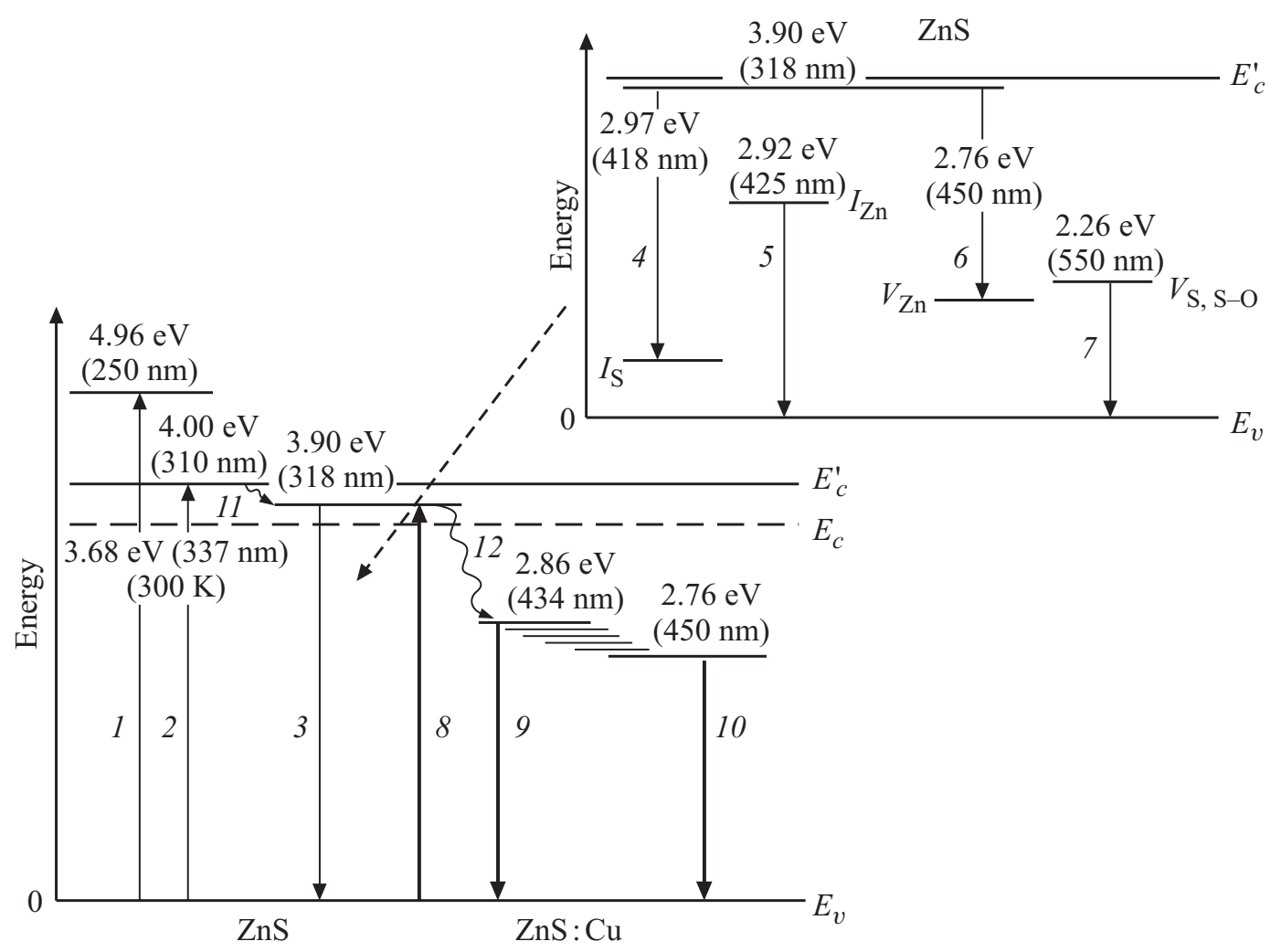

Рис. 5. Схема энергетических состояний и переходов в $\mathrm{ZnS}$ и $\mathrm{ZnS}: \mathrm{Cu}$ в матрице ПММА.

волн 250-310 нм). В отсутствие ионов $\mathrm{Cu}$ дезактивация возбужденных состояний происходит с участием энергетических уровней, расположенных в запрещенной зоне $\mathrm{ZnS}$. За их возникновение ответственны дефекты, которые создают ионы $\mathrm{Zn}$ и $\mathrm{S}$, расположенные в междоузлиях кристаллической решетки $\left(I_{\mathrm{Zn}}\right.$ и $\left.I_{\mathrm{S}}\right)$, и дефекты, связанные с вакансиями данных ионов $\left(V_{\mathrm{Zn}}\right.$ и $\left.V_{\mathrm{S}}\right)$, а также возникающие под влиянием замещения атомов серы кислородом $\left(V_{\mathrm{S}-\mathrm{O}}\right)$. Излучательные переходы показаны стрелками 3-7. Они отражают „самоактивированные“ люминесцентные процессы в ZnS. Из анализа спектров поглощения и люминесценции композиций (рис. 1-4) следует, что активирование $\mathrm{ZnS}$ ионами меди приводит к изменению энергетических потоков. Из процесса дезактивации возбужденных состояний исключаются переходы 3-7, связанные с ZnS. Процессы возбуждения люминесценции и люминесценции $\mathrm{ZnS}: \mathrm{Cu}$ оказываются связанными с системой уровней, расположенных в запрещенной зоне $\mathrm{ZnS}$. Полоса возбуждения люминесценции $\mathrm{ZnS}: \mathrm{Cu}$ (рис. 3; рис. 5, переход 8) перекрывает полосу люминесценции $\mathrm{ZnS}$ (рис. 5, переход 3). Можно предположить, что поглощенная $\mathrm{ZnS}$ энергия практически резонансно возбуждает состояния $\mathrm{ZnS}: \mathrm{Cu}$. Это может быть связано с образованием ионных пар $\mathrm{Zn}-\mathrm{Cu}$ при расположении ионов меди в междоузлиях и вакансиях Zn. Далее процесс дезактивации протекает с участием состояний, связанных с ионами меди (рис. 5, переходы 9 и 10). Диапазон 2.86-2.76 эВ на схеме по- казывает изменение энергии состояний при увеличении концентрации ионов $\mathrm{Cu}$. Наличие диапазона связано с увеличением размера частиц, искажением и увеличением размера элементарной ячейки $\mathrm{ZnS}$ при внедрении ионов меди в междоузлия. Подтверждением данного предположения служит отсутствие в спектрах полос возбуждения люминесценции и люминесценции $\mathrm{ZnS}$.

Влияние матрицы, основу которой составляет ПММА, проявляется в перепоглощении излучения сульфидом цинка. На это указывает отсутствие полос возбуждения люминесценции матрицы в спектрах ПММA/ZnS:Cu (рис. 3). Насыщение люминесценции с увеличением концентрации ионов меди можно связать с образованием ионных пар $\mathrm{Cu}-\mathrm{Cu}$ и $\mathrm{Cu}-\mathrm{Zn}$ и более сложных агрегатов.

\section{Список литературы}

[1] О.В. Овчинников, А.Н. Латышев, М.С. Смирнов. Конденсированные среды и межфазные границы, 7, 413 (2005).

[2] J. Planelles-Aragó, B. Julián-López, E. Cordoncillo, P. Escribano, F. Pelle, B. Viana, C. Sanchez. J. Mater. Chem., 18, 5193 (2008).

[3] Т.Н. Щерба, К.В. Лупандина, М.П. Жиленко, Г.П. Муравьева, Г.В. Эрлих, Г.В. Лисичкин. Изв. АН. Сер. хим., 8, 1547 (2011).

[4] J.M. Montenegro, W.J. Parak, V. Grazu, J.M. de la Fuente, A. Sukhanova, I. Nabiev, S. Agarwal, A. Greiner. Adv. Drug Deliv. Rev., 65 (5), 677 (2013). 
[5] X. Gong, Z. Yang, G. Walters, R. Comin, Z. Nihg, E. Beauregard, V. Adinolfi, O. Voznyy, E.H. Sargent. Nature Photonics, 10 (4), 253 (2016).

[6] С.В. Дайнеко, П.С. Самохвалов, Д. Лыпенко, Г.И. Носова, И.А. Березин, А.В. Якиманский, А.А. Чистяков, И. Набиев. Опт. и спектр., 122 (4), 17 (2017).

[7] М.А. Звайгзне, И.Л. Мартынов, В.А. Кривенков, П.С. Самохвалов, И.Р. Набиев. Опт. и спектр., 122 (1), 76 (2017).

[8] D. Denzler, M. Olschewski, K. Sattler. J. Appl. Phys., 84 (5), 2841 (1998).

[9] Т.Н. Щерба. Автореф. канд. дис. (М., МГУ, 2011).

[10] Е.Ю. Готовцева, А.А. Бирюков, В.А. Светличный. Изв. вузов. Физика, 56 (3), 32 (2013).

[11] В.П. Смагин, Д.А. Давыдов, Н.М. Унжакова, А.А. Бирюков. Журн. неорган. химии, 60 (12), 1734 (2015).

[12] В.П. Смагин, Д.А. Давыдов, Н.М. Унжакова. Патент РФ № 2561287 (2015).

[13] В.П. Смагин, Н.С. Еремина, А.А. Исаева, Ю.В. Ляхова. Неорг. матер., 53 (3), 252 (2017).

[14] Ю.Ю. Бачериков, И.П. Ворона, С.В. Оптасюк, В.Е. Родионов, А.А. Стадник. ФТП, 38 (9), 1025 (2004).

[15] N. Jing-hua, H. Rui-nian, L. Wen-lian, L. Ming-tao, Y. TianZhi. J. Phys. D: Appl. Phys., 39 (11), 2357 (2006).

[16] R.H. Page, K.I. Schaffers, L.D. DeLoach, G.D. Wilke, F.D. Patel, J.B. Tassano, Jr, S. Payne, W. Krupke, K.-T. Chen, A. Burger. IEEE J. Quant. Electron., 33 (4), 609 (1997).

[17] М.Ф. Буланый, А.В. Коваленко, Б.А. Полежаев, Т.А. Прокофьев. ФТП, 43, 745 (2009).

[18] К.А. Огурцов, В.В. Бахметьев, А.М. Абызов, М.Н. Цветкова, М.М. Сычев. Изв. СПб ГТИ (ТУ), 7, 13 (2010).

[19] P. Mukherjee, C.M. Shade, A.M. Yingling, D.N. Lamont, D.H. Waldeck, S. Petoud. J. Phys. Chem. A, 115 (16), 4031 (2011).

[20] P. Mukherjee, R.F. Sloan, C.M. Shade, D.H. Waldeck, S. Petoud. J. Phys. Chem. C, 117 (27), 14451 (2013).

[21] М.А. Джафаров, Е.Ф. Насиров, Р.С. Джафарли. Неорг. матер., 53 (1), 15 (2017).

[22] H. Ehrlich, T. Shcherba, M. Zhilenko, G. Lisichkin. Mater. Lett., 65, 107 (2011).

[23] Н.Г. Пивен, Л.П. Щербак, П.И. Фейчук, С.М. Калитчук, С.Г. Крылюк, Д.В. Корбутяк. Конденсированные среды и межфазные границы, 8 (4), 315 (2006).

[24] В.П. Смагин, А.А. Исаева, Н.С. Еремина, А.А. Бирюков. ЖПХ, 88 (6), 924 (2015).

[25] X. Sun, L. Xie, W. Zhou, F. Pang, T. Wang, A.R. Kost, Z. An. Opt. Express, 21 (7), 8214 (2013).

[26] Э.А. Романов. Автореф. канд. дис. (Ижевск, УдГУ, 2011).

[27] В.Г. Клюев, Т.Л. Майорова, М. Фам Тхи Хаи, В.Н. Семенов. Конденсированные среды и межфазные границы, 11 (1), 58 (2009).

[28] Н.К. Морозова, И.А. Каретников, Д.А. Мидерос, Е.М. Гаврищук, В.Б. Иконников. ФТП, 40 (10), 1185 (2006).

[29] Н.К. Морозова, Д.А. Мидерос, В.Г. Галстян, Е.М. Гаврищук. ФТП, 42 (9), 1039 (2008).

Редактор Л.В. Шаронова

\section{Photoluminescence of $\mathrm{ZnS}: \mathrm{Cu}$ in the matrix of polymethylmethacrylate}

\author{
V.P. Smagin ${ }^{1}$, N.S. Eremina ${ }^{2}$, M.S. Leonov ${ }^{1}$ \\ ${ }^{1}$ Altai State University, \\ 656049 Barnaul, Russia \\ ${ }^{2}$ National Research Tomsk State University, \\ 634050 Tomsk, Russia
}

\begin{abstract}
The method of arising reagents directly in the environment (poly)methyl methacrylate was used to synthesize quantum dots of $\mathrm{ZnS}: \mathrm{Cu}$ fixed in the optically transparent polymer matrix. The light transmittance of the polymetric compositions of the visible spectrum was up to $92 \%(5 \mathrm{~mm})$. Photoluminescence PMMA/ZnS: $\mathrm{Cu}$ is associated with defects of the crystal structure of $\mathrm{ZnS}$ and the system of energy levels located in the zinc sulfide band gap. It depends on the concentration of copper ions, reabsorption of radiation emitted by $\mathrm{ZnS}$ and PMMA, and on other factors.
\end{abstract}

